\title{
Antioxidant Phytochemicals in Fruits and Vegetables: Diet and Health Implications
}

\author{
Ronald L. Prior ${ }^{\mathbf{1}}$ and Guohua Cao \\ U.S. Department of Agriculture, Agriculture Research Service, Jean Mayer Human Nutrition Research Center on \\ Aging at Tufts University, 711 Washington Street, Boston, MA 02111
}

\begin{abstract}
Increased consumption of fruits and vegetables has been associated with protection against various age-related diseases (Ames et al., 1993; Steinberg, 1991). What dietary constituents are responsible for this association is not known, but well-characterized antioxidants, including vitamins $\mathrm{C}$ and $\mathrm{E}$, or $\beta$-carotene, are often assumed to contribute to the observed protection (Ames et al., 1993; Buring and Hennekens, 1997; Gey et al., 1991; Stahelin et al., 1991; Steinberg, 1991; Willett, 1994). However, the results from intervention trials have not been conclusive regarding the protection following supplementation with such antioxidants (Hennekens et al., 1996; Omenn et al., 1996; Priemé et al., 1997; Van Poppel et al., 1995). Recent epidemiological evidence indicates that the putative beneficial effects of a high intake of fruits and vegetables on the risk of diseases of aging may not be exclusively due to these antioxidants (Hertog et al., 1992; Knekt et al., 1997), but other antioxidant phytochemicals contained in fruits and vegetables may be equally important. To critically evaluate the potential roles of these phytochemicals in prevention of agerelated diseases, we will discuss the free radical or oxidative stress theory of aging and present data on the antioxidant capacities of fruits, vegetables, and their phytochemical components, mainly flavonoids.
\end{abstract}

Received for publication 26 May 1999. Accepted for publication 10 Aug. 1999. Mention of a trade name, proprietary product, or specific equipment does not constitute a guarantee by the U.S. Dept. of Agriculture and does not imply its approval to the exclusion of other products that may be suitable.The cost of publishing this paper was defrayed in part by the payment of page charges. Under postal regulations, this paper therefore must be hereby marked advertisement solely to indicate this fact.

${ }^{1}$ To whom reprint requests should be addressed (phone: (617) 556-3311; fax: (617) 556-3299; e-mail: prior@hnrc.tufts.edu).
Reports on the absorption of these flavonoids and the effects of fruit and vegetable intake on the antioxidant status in humans will be reviewed.

\section{FREE RADICAL OR OXIDATIVE STRESS THEORY OF AGING}

Oxygen may be reduced by less than four electrons during normal metabolism to yield partially reduced reactive oxygen metabolites. Many of these reactive species (RS) are free radicals, i.e., they contain an odd number of electrons. Examples of oxygen-derived free radicals include superoxide $\left(\mathrm{O}_{2}^{-*}\right)$, hydroxyl $\left(\mathrm{OH}^{*}\right)$, hydroperoxyl (HOO$)$, peroxyl (ROO*), and alkoxyl (RO*) radicals. Reactive oxygen species that contain an even number of electrons, and thus are not free radicals, include hydrogen peroxide $\left(\mathrm{H}_{2} \mathrm{O}_{2}\right)$ and lipid hydroperoxide $(\mathrm{ROOH})$. Other common RS produced in the body include nitric oxide (NO') and peroxynitrite anion (ONOO$)^{\circ}$. Reactive species are able to initiate lipid peroxidation, a chain reaction, and oxidize other cellular components, such as DNA and proteins (Halliwell, 1997). To deal with RS, the body is equipped with an effective defense system, which includes: enzymes such as superoxide dismutase (SOD), catalase (CAT), glutathione peroxidase (GP), and glutathione reductase (GR); highmolecular-weight antioxidants such as albumin, ceruloplasmin, and ferritin; and an array of low-molecular-weight antioxidants such as ascorbic acid, $\alpha$-tocopherol, $\beta$-carotene, glutathione (GSH), and uric acid. Oxidative stress is a state of imbalance between RS and antioxidants in favor of the former. The free radical or oxidative stress theory of aging states that oxygen-derived free radicals or oxidative stress is the underlying cause of aging and age-related diseases such as cancer, cardiovascular disease, etc. (Harman, 1956, 1981; Yu, 1996). This theory has now been accepted by many gerontologists. 


\section{MEASUREMENT OF ANTIOXIDANT CAPACITY IN FRUITS AND VEGETABLES: OXYGEN RADICAL ABSORBANCE CAPACITY (ORAC) ASSAY}

The ability to determine total antioxidant capacity in fruits and vegetables provides an opportunity to evaluate the theory that protection against free radical damage is a component of the protection observed following their consumption. The ORAC assay developed recently by Cao and coworkers $(1993,1995)$ provides an effective way to evaluate the total antioxidant capacity in fruits and vegetables, in that it combines both inhibition time and inhibition degree of the free radical or oxidant action by an antioxidant into a single quantity using an area under the curve technique for quantitation of the data.

\section{ANTIOXIDANT CAPACITY OF FRUITS AND VEGETABLES}

Studies from our laboratory represent the first attempt to measure total antioxidant capacity of fruits and vegetables (Cao et al., 1996; Guo et al., 1997; Prior et al., 1998; Wang et al., 1996). The antioxidant capacity of common fruits and vegetables, and drinks including green and black teas [Camellia sinensis (L.) Kuntze], commercial fruit juices and wines, were measured with the automated ORAC assay using a peroxyl radical generator $\left(\mathrm{ORAC}_{\mathrm{ROO}}\right)$. Based upon the weight of an edible portion, prunes (Prunus $\times$ domestica L.), raisins (Vitis sp.), blueberries (Vaccinium sp.), cranberries (Vaccinium oxycoccos L.), and blackberries (Rubus sp.) had an antioxidant capacity of $>20$ $\mu \mathrm{mol} \cdot \mathrm{g}^{-1}$ Trolox equivalents (TE) (Trolox: 6-Hydroxy-2,5,7,8tetramethylchroman-2-carboxylic acid). Strawberries (Fragaria $\times$ ananassa Duch.), red raspberries (Rubus idaeus L.), garlic (Allium sativum L.), kale (Brassica oleracea L. Acephala Group), and spinach (Spinacia oleracea L.) had an antioxidant capacity between 10 and 20 $\mu \mathrm{mol} \cdot \mathrm{g}^{-1}$ of TE while brussels sprouts (Brassica oleracea $\mathrm{L}$. Gemmifera Group), alfalfa sprouts (Medicago sativa L.), plums, broccoli (Brassica oleracea L. Botrytis Group) florets, beets (Beta vulgaris L. ssp. vulgaris), oranges [Citrus sinensis (L.) Osbeck], red grapes (Vitis sp.), red bell pepper (Capsicum annuum L.), red cherries (Prunus sp.), and kiwifruit (Actinidia chinensis Planch.) had an antioxidant capacity between 5 and $9.9 \mu \mathrm{mol} \cdot \mathrm{g}^{-1}$ of TE. Fruits and vegetables, such as pink grapefruit (Citrus $\times$ paradisi Macfad.), white grape (Vitus sp.), onion (Allium cepa L.), corn (Zea mays L.), eggplant (Solanum melongena L.), cauliflower (Brassica oleracea L. Botrytis Group), potato (Solanum tuberosum L.), sweetpotato (Ipomoea batatas (L.) Lam.), cabbage (Brassica oleracea L. Capitata Group), leaf lettuce (Lactuca sativa L.), bananas (Musa acuminata Colla), apples (Malus $\times$ domestica Borkh.), carrot (Daucus carota L.), string bean (Phaseolus vulgaris L.), tomatoes (Lycopersicon esculentum Mill.), yellow squash (Cucurbita sp.), pears (Pyrus sp.), iceberg lettuce (Lactuca sativa L.), honeydew melon (Cucumis melo L. Inodorus Group), celery [Apium graveolens L. var. dulce (Mill) Pers.], and cucumber (Cucumus sativus L.) had an antioxidant capacity $<5 \mu \mathrm{mol} \cdot \mathrm{g}^{-1}$ of TE (Cao et al., 1996; Prior et al., 1998; Wang et al., 1996).

Antioxidant capacity of fruits and vegetables may be influenced by genetics as well as environmental factors. We have observed as much as a 3.3-fold difference in antioxidant capacity as well as total phenolics and anthocyanins among species and cultivars of Vaccinium (Prior et al., 1998) and among cultivars of strawberries (Prior et al., unpublished data). Antioxidant capacity, total phenolics, and anthocyanins of two cultivars of rabbiteye blueberry (V. ashei Reade) also increased with maturity at harvest (Prior et al., 1998). Total antioxidant capacity may be an effective tool for use in fruit and vegetable breeding programs designed to increase antioxidant components available for human consumption.

Little has been done to determine effects of cooking and/or processing on the measured antioxidant capacity. Cooking of kale produced a small $(10 \%$ to $15 \%)$ decline in antioxidant capacity, whereas steaming of blueberries for 5 min seemed to increase the quantities of antioxidant phytochemicals (unpublished data) that could be extracted and measured using the ORAC assay.

We calculated that the contribution of vitamin $\mathrm{C}$ to the total $\mathrm{ORAC}_{\mathrm{ROO}}$ activity of these fruits was usually $<15 \%$, except for kiwifruit and honeydew melon (Prior et al., 1998; Wang et al., 1996). This suggests that the major source of antioxidant capacity of most fruits and commercial fruit juices may not be vitamin $\mathrm{C}$, but other antioxidant phytochemicals. There have been very few other published attempts at quantitating antioxidant capacity in foods. However, there has been some interest, using various analytical techniques, in quantitating antioxidant activity in grape wines, garlic extracts, and herbs. Whitehead et al. (1995), who used a chemiluminescent reaction to measure the antioxidant capacity of red wine, reported a variation of 10.0 to $20.7 \mu \mathrm{mol} \cdot \mathrm{mL}^{-1}$ of TE in antioxidant capacity in nine different red wines with a mean of $15.4 \mu \mathrm{mol} \cdot \mathrm{mL}^{-1}$ of TE. This value is similar to the value of $12.3 \mu \mathrm{mol} \cdot \mathrm{mL}^{-1}$ of TE which Cao and coworkers (1995) measured in a red wine using the ORAC $_{\text {ROo }}$ method. Whitehead et al. (1995) also reported that four white wines had antioxidant capacities of $<2.0 \mu \mathrm{mol} \cdot \mathrm{mL}^{-1}$ of TE, which agrees closely with the value of $2.3 \mu \mathrm{mol} \cdot \mathrm{mL}^{-1}$ of TE observed by Cao et al. (1995). Campos and Lissi (1996) used the Trolox Equivalent Antioxidant Capacity (TEAC) method to measure total antioxidant capacity of Chilean wines and found that red wines had values between 25.1 and $33.3 \mu \mathrm{mol} \cdot \mathrm{mL}^{-1}$ of TE, and white wines ranged from 2.9 to 5.2 $\mu \mathrm{mol} \cdot \mathrm{mL}^{-1}$ of TE. Using a phenol antioxidant index based upon phenol concentration and inhibition of low-density lipoprotein (LDL) oxidation, Vinson and Hontz (1995) concluded that red wines had a significantly higher antioxidant index than white wines and thus were a better source of antioxidants. Frankel and coworkers (1995) also found that red wines were more effective in the inhibition of LDL oxidation than white wines. Vinson and coworkers (1998) used similar techniques to evaluate vegetables. A high antioxidant activity has also been found in a garlic extract (Popov et al., 1994), selected oriental herb extracts (Kim et al., 1994), and leaves from Vernonia amygdalina, a small tree that grows throughout tropical Africa (Igile et al., 1994).

\section{FLAVONOIDS PRESENT IN FRUITS AND VEGETABLES}

One hypothesis that has been advanced is that the protection against diseases, such as cancer and cardiovascular diseases, can be attributed to a large class of antioxidant phytochemicals, termed flavonoids, contained in fruits and vegetables. The phytochemicals considered for the purposes of this review will, thus, refer primarily to the flavonoids found in fruits, vegetables, nuts, seeds, stems, and flowers, as well as in tea and wine. Flavonoids are diphenylpropanes that commonly occur in plants; $>4000$ flavonoids have been identified. The common family members of flavonoids include flavones, isoflavones, flavanones, anthocyanins, flavans, and proanthocyanidins.

Flavonoids have long been recognized to possess antiallergic, antiinflammatory, antiviral, antiproliferative, and anticarcinogenic activities (Middleton and Kandaswami, 1993). No attempt will be made in this review to cover the diverse enzymes and metabolic processes that are affected by the numerous flavonoids. These studies have been summarized in several reviews (Cook and Samman, 1996; Dakora, 1995; Formica and Regelson, 1995; Middleton and Kandaswami, 1993; Stavric, 1994). Flavonoids are generally considered nonessential dietary nutrients. However, of historical significance, in light of possible nutritional implications of the consumption of flavonoids, is the early observation that a mixture of two flavonoids called citrin (eriodictyol and hesperidin) was considered to possess vitamin-like activity. The term "vitamin P" was coined to indicate that this material could decrease capillary permeability (and fragility), prolong the life of marginally scorbutic guinea pigs, and reduce the signs of hypovitaminosis $\mathrm{C}$ in experimental animals. Although socalled vitamin $P$ ultimately did not fulfill the definition of a vitamin and the term was subsequently abandoned, there was nonetheless a strong indication that these two flavonoids had potent antioxidant-dependent, vitamin-C-sparing activity. We do not know much about possible synergistic or additive effects of flavonoids and the nutrient antioxidants, such as vitamins $\mathrm{C}$ or $\mathrm{E}$. The view that flavonoids are irrelevant to human health and/or disease may need to be modified in view of the potentially health-promoting activities of the flavonoids that have recently been reported in experimental (Middleton and Kandaswami, 1993) and epidemiological studies (Hertog et al., 1993a, 1993b). 


\section{ANTIOXIDANT ACTIVITIES OF FLAVONOIDS}

Because of the prevalence of flavonoids in foods, we and others (Cao et al., 1997; Rice-Evans et al., 1996; Wang et al., 1997) have undertaken studies to determine the antioxidant activity associated with flavonoids of different chemical structures. We found that, generally, the more $\mathrm{OH}$ substitutions, the stronger the $\mathrm{ORAC}_{\mathrm{ROO}}$ activity. Weak $\mathrm{ORAC}_{\mathrm{ROO}}$ activity $\left(0.2-0.6 \mu \mathrm{mol} \cdot \mathrm{mol}^{-1}\right.$ of TE) was observed for flavones with single $\mathrm{OH}$ substitutions on the $3,6,2^{\prime}$, or $4^{\prime}$ position and in flavanones with single $\mathrm{OH}$ substitutions in the 7,2', $3^{\prime}, 4^{\prime}$, or $7^{\prime}$ position (Cao et al., 1997). A flavone with a single $\mathrm{OH}$ substitution on the 5 position, however, had no detectable ORAC $_{\mathrm{ROO}}$ activity, while a flavanone with a single $\mathrm{OH}$ substitution on the 6 position had an $\mathrm{ORAC}_{\mathrm{ROO}}$ activity of $1.36 \mathrm{TE}$, even stronger than Trolox. With compounds having the same basic chemical structure, the $\mathrm{ORAC}_{\mathrm{ROO}}$ activity was proportional to the number of $\mathrm{OH}$ substitutions on the flavone or flavanone structure. Kaempherol, quercetin, and myricetin, which have 4, 5, and $6 \mathrm{OH}$ substitutions, respectively,

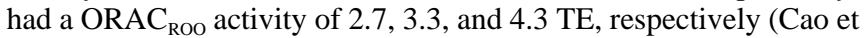
al., 1997). This is consistent with the inhibitory effects of these flavones (kaempherol < quercetin < myricetin) on platelet aggregation induced by a combination of adenosine diphosphate (ADP), collagen, and platelet activating factor (Tzeng et al., 1991). Measurement of antioxidant activity by the TEAC method did not rank these flavones in a similar order (Rice-Evans et al., 1995, 1996). However, several techniques have identified the importance of 3', 4' di-OH substitution in the $\mathrm{B}$ ring to the antioxidant activity of flavonoids, including techniques such as: 1) the formation and decay of the flavonoid aroxyl radicals (Bors et al., 1990); 2) the ability of flavonoids to quench the chromogenic radical cation, 2,2'-azinobis(3-ethylbenzothiazoline 6sulfonate (ABTS. ${ }^{+}$) (Rice-Evans et al., 1995); 3) the protection of lysosomes by flavonoids against oxygen radicals (Decharneux et al., 1992); and 4) the inhibitory effects of flavonoids on the release of reactive oxygen species by stimulated human neutrophils (Limassett et al., 1993).

The flavones and flavanones that contain multiple $\mathrm{OH}$ substitutions have very strong antioxidant activities against peroxyl radicals. For example, the $\mathrm{ORAC}_{\mathrm{ROO}}$ activities of myricetin, quercetin, luteolin, fustin, eriodictyol, and taxifolin were 4.32, 3.29, 3.57, 3.91, 3.41, 3.59 TE, respectively, while $\alpha$-tocopherol, ascorbic acid, $\beta$-carotene, GSH, uric acid, and bilirubin had $\mathrm{ORAC}_{\mathrm{ROO}}$ values of 1.0, 0.52-1.12, 0.64, 0.68, 0.92, and 0.84 TE, respectively (Cao et al., 1993; Pieri et al., 1994). This observation means that the stoichiometric factor (i.e., the number of peroxyl radicals trapped per molecule antioxidant) of these flavonoids is $\approx 6-9$, since the stoichiometric factor of Trolox is 2 (Burton et al., 1983). Copper-initiated prooxidant actions were observed for some flavonoids, as well as for other antioxidants, including ascorbic acid and $\alpha$-tocopherol. However, this may not be important in vivo, where copper ions will be largely sequestered, except perhaps in certain metal overload diseases. The prevention of iron-increased lipid peroxidation in hepatocytes by some flavonoids, including quercetin, has been reported (Morel et al., 1993; 1994).

Using the automated $\mathrm{ORAC}_{\mathrm{ROO}}$ assay, we have also determined the antioxidant capacity of 14 anthocyanins, including the aglycones delphinidin, cyanidin, pelargonidin, malvidin, and peonidin, and the glycosides kuromanin (cyanidin-3-glucoside), keracyanin (cyanidin3-rhamnoglucoside), ideain (cyanidin-3-galactoside), cyanin (cyanidin-3,5-diglucoside), callistephin (pelargonidin-3-glucoside), pelargonin (pelargonidin-3,5-diglucoside), oenin (malvidin-3-glucoside), malvin (malvidin-3,5-diglucoside), and peonidin-3-glucoside. All of these compounds showed strong antioxidant activities (Wang et al., 1997). Among them, kuromanin had the highest ORAC, which was $3.5 \times$ stronger than Trolox. Pelargonin had the lowest ORAC but was still as potent as Trolox (Wang et al., 1997).

\section{ABSORPTION OF ANTIOXIDANT FLAVONOIDS AND EFFECTS OF INCREASING FRUIT AND VEGETABLE INTAKE ON ANTIOXIDANT STATUS IN HUMANS}

Although strong antioxidant properties of the various flavonoids have been demonstrated in numerous biological systems in vitro, little information is available on their absorption and contribution to the overall antioxidant status in vivo. Absorption of flavonoids from the diet was long assumed to be negligible, as most of the flavonoids, except catechins, are present in plants bound to sugars as glycosides, and these glycosides were considered nonabsorbable. Contrary to the common belief that only flavonoid aglycones can be absorbed, the accumulating evidence indicates that flavonoid glycosides are easily absorbed in humans and rats without prior hydrolysis by microorganisms.

To their surprise, Hollman and coworkers (1995) found in ileostomy subjects that the quercetin glycosides from onions were absorbed far better than the pure aglycones. They also found in healthy subjects that such glycosides were absorbed and were eliminated slowly through the day (Hollman et al., 1996). The bioavailability of both quercetin from apples and pure quercetin-3-rutinoside was both $30 \%$ relative to onions (Hollman et al., 1997). Rutin, and other quercetin glycosides, as well as an anthocyanin, were detected simultaneously in plasma from nonsupplemented humans (Paganga and Rice-Evans, 1997). Recently, Prior and Cao (1999a) observed the absorption and appearance in plasma within $60 \mathrm{~min}$ of two cyanidin glucosides from elderberry (Sambucus nigra L.) fruits in normal human subjects. What appeared to be the same compounds also were observed unmetabolized in the urine (Prior and Cao, 1999a), based upon HPLC retention times and absorption spectra. Absorption of flavonoid glycosides has also been observed in rats (Horwitt, 1933; Morazzoni et al., 1991). A recent study suggests that quercetin glucosides are capable of interacting with the sodium-dependent glucose transport receptors in the mucosal epithelium and may therefore be absorbed by the small intestine in vivo (Gee et al., 1998).

The effects of fruit and vegetable intake on in vivo antioxidant status also support the absorption of flavonoids in humans. We found in 36 healthy nonsmokers that daily intake of the total antioxidants, measured as ORAC, from fruits and vegetables was significantly correlated with the fasting plasma antioxidant capacity. Increasing the consumption of fruits and vegetables from the usual five servings/day to the experimental 10 servings/day resulted in a significant increase of plasma antioxidant capacity (Cao et al., 1998a). Increased plasma antioxidant capacity and/or plasma total polyphenols in humans were also reported after the consumption of red wine (Cao et al., 1998b; Serafini et al., 1998; Whitehead et al., 1995) and grape juice (Day et al., 1997). A reduced sensitivity to oxidation of plasma and/or low density lipoprotein was observed in subjects consuming red wine in one study (Fuhrman et al., 1995) but not in another (de Rijke et al., 1996)

\section{DIETARY INTAKE OF FLAVONOIDS}

Kuhnau (1976) estimated that the average intake of all flavonoids combined was $\approx 1 \mathrm{~g} \cdot \mathrm{d}^{-1}$. These results have been widely quoted; however, more recent results (Hertog et al., 1993a, 1993b) suggest that these values may be $\approx 5$-fold higher than the typical intake in a Western population. Hertog and coworkers (1993a, 1993b) determined that the intake of flavonoids (quercetin, kaempferol, myricetin, apigenin, and luteolin) among 4112 adults was $23 \mathrm{mg} \cdot \mathrm{d}^{-1}$, with the most important flavonoid being quercetin with a mean intake of $16 \mathrm{mg} \cdot \mathrm{d}^{-1}$. However, a limitation in these data is a lack of quantitative information on all the flavonoid compounds in fruits and vegetables.

Anthocyanins are a group of flavonoids that have not received much attention in terms of possible implications for human nutrition. The anthocyanins (i.e., cyanidin, delphinidin, malvidin, peonidin, and pelargonidin) have a high antioxidant capacity as measured by $\mathrm{ORAC}_{\mathrm{ROO}}$ (Wang et al., 1997). Mazza and Miniati (1993) have completed a comprehensive review of anthocyanins present in fruits, vegetables, and grains; however, much of the earlier literature cited lacks quantitative data. The content of anthocyanins in fruit clearly seems high compared with that of the other flavonoids evaluated by Hertog et al. (1993a, 1993b) (quercetin, kaempferol, myricetin, apigenin, and luteolin). In fruits such as blackberry, blueberry, cranberry, raspberry, strawberry, and boysenberry (Rubus sp.), anthocyanin content may range from 200 to $4950 \mathrm{mg} \cdot \mathrm{kg}^{-1}$ of fresh fruit. In blueberries, the anthocyanin content is 10 to $200 \times$ the quercetin content. Consumption 
of 100 to $150 \mathrm{~g}(\approx 1 \mathrm{cup})$ of these fruits could easily result in an intake of 100 to $200 \mathrm{mg}$ of anthocyanins, which is well above the average intake of flavonoids indicated by Hertog et al. (1993a, 1993b).

Intake of total antioxidant capacity expressed as ORAC equivalents $\left(\mu \mathrm{mol} \cdot \mathrm{d}^{-1}\right.$ of TE) is in the range of 1200 to 1640 ORAC equivalents per day for individuals consuming two to five servings of fruits and vegetables per day (Cao et al., 1998a). From ORAC measurements of individual flavonoids, we have observed a ratio of antioxidant capacity (ORAC) to total phenols $\left(\mu \mathrm{mol} \cdot \mathrm{mg}^{-1}\right.$ of TE) ranging from 2 to 13 with a mean of $7.2 \pm 0.4(n=33)$ (Prior and Cao, 1999 b). The same ratio in polyphenolics extracted from food samples is $\approx 11 \mu \mathrm{mol} \cdot \mathrm{mg}^{-1} \mathrm{TE}$ of total phenolics (mean of 20 samples) (Prior et al., unpublished data). Based upon this ratio, a total antioxidant capacity intake of 1200 to 1640 ORAC equivalents would provide a total phenolic intake of 109 to $149 \mathrm{mg}$ for individuals consuming two to five servings of fruits and vegetables per day and up to $336 \mathrm{mg}$ if 10 servings (3700 ORAC equivalents) of fruits and vegetables are consumed (Cao et al., 1998a). Vinson et al. (1998) estimated that the per capita consumption of total and free phenolics from vegetables is 242 and $116 \mathrm{mg} \cdot \mathrm{d}^{-1}$, respectively. Based upon our data from individuals consuming 3700 ORAC equivalents on in vivo antioxidant capacity, an increase of 1000 to 2000 ORAC equivalents per day to the average diet may be needed to bring about some of the beneficial health effects of fruit and vegetable consumption.

\section{CONCLUSION}

Due to accumulating evidence demonstrating the absorption of dietary flavonoids in humans and significant contributions of phytochemicals such as flavonoids to the antioxidant capacity measured in fruits and vegetables, we conclude that these phytochemicals can be an important source of dietary antioxidants and may be responsible for the health benefits observed with increased consumption of fruits and vegetables.

\section{Literature Cited}

Ames, B.M., M.K. Shigena, and T.M. Hagen. 1993. Oxidants, antioxidants and the degenerative diseases of aging. Proc. Natl. Acad. Sci. 90:7915-7922.

Bors, W., W. Heller, C. Michel, and M. Saran. 1990. Flavonoids as antioxidants: Determination of radical-scavenging efficiencies. Meth. Enzymol. 186:343-355.

Buring, J.E. and C.H. Hennekens. 1997. Antioxidant vitamins and cardiovascular disease. Nutr. Rev. 55:S53-S60.

Burton, G.W., L. Hughes, and K.U. Ingold. 1983. Antioxidant activity of phenols related to vitamin E. Are there chain-breaking antioxidants better than $\alpha$-tocopherol? J. Amer. Chem. Soc. 105:5950-5951.

Cao, G., H.M. Alessio, and R.G. Cutler. 1993. Oxygen-radical absorbance capacity assay for antioxidants. Free Radical Biol. Med. 14:303-311.

Cao, G., S.L. Booth, J.A. Sadowski, and R.L. Prior. 1998a. Increases in human plasma antioxidant capacity following consumption of controlled diets high in fruits and vegetables. Am. J. Clin. Nutr. 68:1081-1087.

Cao, G. and R.L. Prior. 1999. Anthocyanins are detected in human plasma after oral administration of an elderberry extract. Clin. Chem. 45:574-576.

Cao, G., R.M. Russell, and R.L. Prior. 1998b. Responses in serum antioxidant capacity following consumption of strawberries, spinach, red wine or vitamin C in elderly subjects. J. Nutr. 128:2383-2390.

Cao, G., E. Sofic, and R.L. Prior. 1996. Antioxidant capacity of tea and common vegetables. J. Agr. Food Chem. 44:3426-3431.

Cao, G., E. Sofic, and R.L. Prior. 1997. Antioxidant and prooxidant behavior of flavonoids: Structure-activity relationships. Free Radical Biol. Med. 22:749-760.

Cao, G., C.P. Verdon, A.H.B. Wu, H. Wang, and R.L. Prior. 1995. Automated oxygen radical absorbance capacity assay using the COBAS FARA II. Clin. Chem. 41:1738-1744.

Campos, A.M. and E.A. Lissi. 1996. Total antioxidant potential of Chilean wines. Nutr. Res. 16:385-389.

Cook, N.C. and S. Samman. 1996. Flavonoids-Chemistry, metabolism, cardioprotective effects, and dietary sources. Nutr. Biochem. 7:66-76.

Dakora, F.D. 1995. Plant flavonoids: Biological molecules for useful exploitation. Austral. J. Plant Physiol. 22:87-99.

Day, A.P., H.J. Kemp, C. Bolton, M. Hartog, and D. Stansbie. 1997. Effect of concentrated red grape juice consumption on serum antioxidant capacity and low-density lipoprotein oxidation. Ann. Nutr. Metab. 41:353-357.
Decharneux, T., F. Dubois, C. Beauloye, S.W.D. Coninck, and R. Wattiaux. 1992. Effect of various flavonoids on lysosomes subjected to an oxidative or an osmotic stress. Biochem. Pharmacol. 44:1243-1248.

de Rijke, Y.B., P.N.M. Demacker, N.A. Assen, L.M. Sloots, M.B. Katan, and A.F.H. Stalenhoef. 1996. Red wine consumption does not affect oxidizability of low-density lipoproteins in volunteers. Amer. J. Clin. Nutr. 63:329-334.

Formica, J.V. and W. Regelson. 1995. Review of the biology of quercetin and related bioflavonoids. Food Chem. Toxicol. 33:1061-1080.

Frankel, E.N., A.L. Waterhouse, and P.L. Teissedre. 1995. Principal phenolic phytochemicals in selected California wines and their antioxidant activity in inhibiting oxidation of human low-density lipoproteins. J. Agr. Food Chem. 43:890-894.

Fuhrman, B., A. Lavy, and M. Aviram. 1995. Consumption of red wine with meals reduces the susceptibility of human plasma and low-density lipoprotein to lipid peroxidation. Amer. J. Clin. Nutr. 61:549-554.

Gee, J.M., M.S. DuPont, M.J.C. Rhodes, and I.T. Johnson. 1998. Quercetin glucosides interact with the intestinal glucose transport pathway. Free Radical Biol. Med. 25:19-25.

Gey, K.F., P. Puska, P. Jordan, and U.K. Moser. 1991. Inverse correlation between plasma vitamin $\mathrm{E}$ and mortality from ischemic heart disease in cross-cultural epidemiology. Amer. J. Clin. Nutr. 53:326C-334S.

Guo, C., G. Cao, E. Sofic, and R.L. Prior. 1997. High performance liquid chromatography coupled with coulometric array detection of electroactive components in fruits and vegetables: Relationship to oxygen radical absorbance capacity. J. Agr. Food Chem. 45:1787-1796.

Halliwell, B. 1997. Antioxidants and human disease: A general introduction. Nutr. Rev. 55:S44-49.

Harman, D. 1956. Aging: A theory based on free radical and radiation chemistry. J. Gerontol. 11:298-300.

Harman, D. 1981. The aging process. Proc. Natl. Acad. Sci. USA 78:7124-7128.

Hennekens, C.H., J.E. Buring, J.E. Manson, M. Stampfer, B. Rosner, N.R.Cook, C. Belanger, F. LaMotte, J.M. Gaziano, P.M. Ridker, W. Willett, and R. Peto. 1996. Lack of effect of long-term supplementation with beta carotene on the incidence of malignant neoplasms and cardiovascular disease. New Engl. J. Med. 334:1145-1149.

Hertog, M.G.L., E.J.M.Feskens, P.C.H. Hollman, M.B. Katan, and D. Kromhout. 1993a. Dietary antioxidant flavonoids and the risk of coronary heart disease: The Zutphen elderly study. Lancet 342:1007-1011.

Hertog, M.G.L.,P.C.H. Hollman, and M.B. Katan. 1992. Content of potentially anticarcinogenic flavonoids of 28 vegetables and 9 fruits commonly consumed in the Netherlands. J. Agr. Food Chem. 40:2379-2383.

Hertog, M.G.L.,P.C.H. Hollman, M.B. Katan, and D. Kromhout. 1993b. Intake of potentially anticarcinogenic flavonoids and their determinants in adults in the Netherlands. Nutr. Cancer 20:21-29.

Hollman, P.C.H., J.H.M. De Vries, S.D. Van Leeuwen, M.J.B. Mengelers, and M.B. Katan. 1995. Absorption of dietary quercetin glycosides and quercetin in healthy ileostomy volunteers. Amer. J. Clin. Nutr. 62:1276-1282.

Hollman, P.C.H., M.V.D. Gaag, M.J.B. Mengelers, J.M.P. Van Trijp, J.H.M. De Vries, and M.B. Katan. 1996. Absorption and disposition kinetics of the dietary antioxidant quercetin in man. Free Radical Biol. Med. 21:703-707.

Hollman, P.C.H., J.M.P. Van Trijp, M.N.C.P. Buysman, M.S. van der Gaag, M.J. Mengelers, J.H. de Vries, and M.B. Katan. 1997. Relative bioavailability of the antioxidant flavonoid quercetin from various foods in man. Fed. European Biochem. Soc. Lett. 418:152-156.

Horwitt, M.K. 1993. Observations on behavior of the anthocyanin pigment from concord grapes in the animal body. Proc. Soc. Expt. Biol. Med. 30:949-951.

Igile, G.O., W. Oleszek, M. Jurzysta, S. Burda, M. Fafunso, and A.A. Fasanmade. 1994. Flavonoids from Veronia amugdalina and their antioxidant activities. J. Agr. Food Chem. 42:2445-2448.

Kim, S.Y., J.H. Kim, S.K. Kim, M.J. Oh, and M. Jung. 1994. Antioxidant activities of selected oriental herb extracts. J. Amer. Oil Chem. Soc. 71:633-640.

Knekt, P., R. Jarvinen, R. Seppanen, M. Heliövaara, L. Teppo, and A. Aromaa. 1997. Dietary flavonoids and the risk of lung cancer and other malignant neoplasms. Amer. J. Epidemiol. 146:223-230.

Kuhnau, J. 1976. The flavonoids. A class of semi-essential food components: Their role in human nutrition. Wild. Rev. Nutr. Diet. 24:117-191.

Limassett, B., C. Doucen, J. Dore, T. Ojasoo, M. Damon, and A.C. Paulet. 1993. Effects of flavonoids on the release of reactive oxygen species by stimulated human neutrophils: Multivariate analysis of structure-activity relationships (SAR). Biochem. Pharmacol. 46:1257-1271.

Mazza, G. and E. Miniati. 1993. Anthocyanins in fruits, vegetables, and grains, p. 1-362. In: G. Mazza and E. Miniati (eds.). CRC Press, Boca Raton, Fla.

Middleton, J.E. and C. Kandaswami. 1993. The impact of plant flavonoids on mammalian biology: Implications for immunity, inflammation and cancer, p. 1167-1179. In: J.B. Harborne (ed.). The flavonoids: Advances in research since 1986. Chapman \& Hall, London. 
Morazzoni, P., S. Livio, A. Scilingo, and S. Malandrino. 1991. Vaccinium myrtillus anthocyanosides pharmacokinetics in rats. Arzneim. Forsch./ Drug Res. 41:128-131.

Morel, I., G. Lescoat, P. Cillard, and J. Cillard. 1994. Role of flavonoids and iron chelation in antioxidant action. Meth. Enzymol. 243:437-443.

Morel, I., G. Lescoat, P. Cogrel, O. Sergent, N. Pasdeloup, P. Brissot, P. Cillard, and J. Cillard. 1993. Antioxidant and iron-chelating activities of the flavonoids catechin, quercetin and diosmetin on iron-loaded rat hepatocyte cultures. Biochem. Pharmacol. 45:13-19.

Omenn, G.S., G.E. Goodman, M.D. Thornquist, J. Balmes, M.R. Cullen, A. Glass, J.P. Keogh, F.L. Meyskens, B. Valanis, J.H. Williams, S. Barnhart and S. Hammar. 1996. Effects of a combination of beta carotene and vitamin A on lung cancer and cardiovascular disease. New Engl. J. Med. 334:1150-1155.

Paganga, G. and C.A. Rice-Evans. 1997. The identification of flavonoids as glycosides in human plasma. Fed. European Biochem. Soc. Lett. 401:78-82.

Pieri, C., M. Marra, F. Moroni, R. Recchioni, and F. Marcheselli. 1994. Melatonin: A peroxyl radical scavenger more effective than vitamin E. Life Sci. 55:271-276.

Popov, I., A. Blumstein, and G. Lewin. 1994. Antioxidant effects of aqueous garlic extract. 1st Communication: Direct detection using the photochemiluminescence. Arzneim. Forsch./Drug Res. 44:602-604.

Priemé, H., S. Loft, K. Nyyssönen, J.T. Salonen, and H.E. Poulsen. 1997. No effect of supplementation with vitamin E, ascorbic acid, or coenzyme Q10 on oxidative damage estimated by 8-oxo-7,8-dihydro-2'-deoxyquanosine excretion in smokers. Amer. J. Clin. Nutr. 65:503-507.

Prior, R.L. and G. Cao 1999a. Elderberry anthocyanins are absorbed and affect in vivo antioxidant status in humans. Oxygen Club Soc. of California, 1999 World Congr., Book of Abstr., p 207. (Abstract.)

Prior, R.L. and G. Cao. 1999b. Variability in dietary antioxidant related natural product supplements: The need for methods of standardization. J. Amer. Neutraceut. Assoc. 2(2):46-56.

Prior, R.L., G. Cao, A. Martin, E. Sofic, J. McEwen, C. O'Brien, N. Lischner, M. Ehlenfeldt, W. Kalt, G. Krewer, and C.M. Mainland. 1998. Antioxidant capacity as influenced by total phenolic and anthocyanin content, maturity and variety of Vaccinium species. J. Agr. Food Chem. 46:2686-2693.

Rice-Evans, C.A., N.J. Miller, P.G. Bolwell, P.M. Bramley, and J.B. Pridham. 1995. The relative antioxidant activities of plant-derived polyphenolic flavonoids. Free Radical Res. 22:375-383.

Rice-Evans, C.A., N.J. Miller, and G. Paganga. 1996. Structure-antioxidant activity relationships of flavonoids and phenolic acids. Free Radical Biol. Med. 20:933-956.

Serafini, M., G. Maiani, and A. Ferro-Luzzi. 1998. Alcohol-free red wine enhances plasma antioxidant capacity in humans. J. Nutr. 128:1003-1007.

Stahelin, H.B., K.F. Gey, M. Eichholzer, and E. Ludin. 1991. $\beta$-Carotene and cancer prevention: The Basel study. Amer. J. Clin. Nutr. 53:265S-269S.

Stavric, B. 1994. Quercetin in our diet: From potent mutagen to probable anticarcinogen. Clin. Biochem. 27:245-248.

Steinberg, D. 1991. Antioxidants and atherosclerosis: A current assessment. Circulation 84:1420-1425.

Tzeng, S.H., W.C. Ko, F.N. Ko, and C.M. Teng. 1991. Inhibition of platelet aggregation by some flavonoids. Thrombosis Res. 64:91-100.

Van Poppel, G., H.E. Poulsen, and S. Loft. 1995. No influence of beta carotene on oxidative damage in male smokers. J. Natl. Cancer Inst. 87:310-311.

Vinson, J.A., Y. Hao, X. Su, and L. Zubik. 1998. Phenol antioxidant quantity and quality in foods: Vegetables. J. Agr. Food Chem. 46:3630-3634.

Vinson, J.A. and B.A. Hontz. 1995. Phenol antioxidant index: Comparative antioxidant effectiveness of red and white wines. J. Agr. Food Chem. 43:401-403.

Wang, H., G. Cao, and R.L. Prior. 1996. Total antioxidant capacity of fruits. J. Agr. Food Chem. 44:701-705.

Wang, H., G. Cao, and R.L. Prior. 1997. The oxygen radical absorbing capacity of anthocyanins. J. Agr. Food Chem. 45:304-309.

Whitehead, T.P., D. Robinson, S. Allaway, J. Syms, and A. Hale. 1995. Effect of red wine ingestion on the antioxidant capacity of serum. Clin. Chem. 41:32-35.

Willett, W.C. 1994. Micronutrients and cancer risk. Amer. J. Clin. Nutr. 59:162S-165S

Yu, B.P. 1996. Aging and oxidative stress: Modulation by dietary restriction. Free Radical Biol. Med. 21:651-668. 